\title{
Strategies for Optimal Deployment of Related Clones into Seed Orchards
}

\author{
By D. DanusevičIUUs ${ }^{\left.1), 2),{ }^{*}\right)}$ and D. LindGRen ${ }^{3)}$
}

(Received $24^{\text {th }}$ October 2006)

\begin{abstract}
This study deals with how the deployed proportion of each candidate clone can be decided at the establishment of a seed orchard when the breeding values are available for each candidate in a population of unrelated half-sib families. The following deployment strategies were compared: (a) truncation selection by selecting the clones with the breeding values exceeding certain threshold and deploying equal number of ramets (Truncation strategy); (b) truncation selection by selecting only one best individual within each family (Truncation unrelated); (c) maximizing gain at a given effective clone number (Linear deployment); (d) linear deployment by selecting one best individual within each family (Linear deployment unrelated) and (e) maximizing net gain at a given gene diversity (Optimal proportions). The study focused on the latest alternative and described its superiority and characteristics for a number of possible typical cases. The genetic gain adjusted for predicted inbreeding depression (Net gain), gene diversity and effective clone number were considered as the main ranking criteria.

The strategies optimizing the number of related individuals and the linear deployment strategy with restriction on relatedness returned the highest Net gain. If there is a large diversity to select from (the status number of the candidates is more than 8 times greater than the status number desired in the seed orchard), a relatively simple advice is to select the best individual within the best families and deploy the clones linearly according to their breeding values (the number of families selected depends on the desired status number). If the diversity available to select from is small, it seems recommendable to allow half-sibs among the selections and use the Optimal proportions deployment strategy. As the breeding cycles proceed, the status number of the candidate population will decrease and the Optimal proportions strategy is likely to become more favorable.
\end{abstract}

Key words: co-ancestry, gene diversity, genetic gain, inbreeding, seed orchard, status number.

\section{Introduction}

Conventional seed orchard deployment strategies relied on simple truncation selection: selecting the candidates with breeding values above a certain threshold and deploying the candidates in equal proportions (ZoBel and TALBERT, 1984). Although simplicity is

1) Lithuanian Forest Research Institute, Liepu 1, Girionys, LT-53101, Kaunas district, Lithuania.

2) Faculty of Forestry, Lithuanian Agricultural University, LT-4324, Kaunas-Akademija, Lithuania.

3) Department of Forest Genetics and Plant Physiology, Swedish University of Agricultural Sciences, S-901 83 Umeå, Sweden.

*) Corresponding author: DARIUS DANUsEvičIUs, Tel. +370-37547-289, Fax +370-37-547-446. E-mail: darius.danusevicius@ takas.lt regarded as an advantage, LINDGREN (1974) suggested that deployment of candidates related to their breeding value may be a more efficient approach. If the candidates are unrelated, the deployment of clones in proportions linearly related to their breeding value is the most efficient strategy to maximise genetic gain (LINDGREN and Matheson, 1986). In advanced breeding cycles, however, the candidates tend to be related and the linear deployment strategy does not guarantee an optimum solution. It may even be risky in case of deployment of relatives with high numbers of ramets (WooDs and HEAman, 1989). The emphasis on breeding value of related candidates may increase relatedness, hence inbreeding in the orchard to harmful levels (OLSSON, 2001; WANG TONGLI et al., 2003). One simple approach to cope with the negative effects of relatedness is to introduce constraints on relatedness, such as restricting candidates to say, the one top-ranking individual per family and then use linear deployment for the ramet number. Is there a better deployment solution?

The first generations of seed orchards of conifers were often designed with relatively large numbers of clones (KANG, 2001). The phenotypically selected plus trees were almost equally superior and the strategy was to use large numbers to provide diversity for further breeding (HodGe and White, 1993). It was easy to obtain diverse material as plus trees were vast in number and the species were of long rotation with a tag on diversity concern over the rotation (KJÆR, 1995). After the breeding values of the candidates to be deployed were estimated in the progeny tests, the problem of optimal deployment becomes important. Selection of less but best genotypes will return more gain, however, what is the optimum limit of diversity and is the selection of relatives worth the risk of reduced diversity? Selection considering related clones to seed orchards was investigated by OLsson et al. (2001). A selection algorithm, which considered the reduced growth due to inbreeding depression if related clones were selected, was applied. Total exclusion of related clones in seed orchards can be argued to be a doubtful solution, as related clones may offer much higher breeding value than unrelated alternatives, and the resulting losses by inbreeding if some relatedness was tolerated may be quite low (OLSSON et al., 2001). Theoretical improvements concerning the effective population size of seed orchards and their crops were proposed by LINDGREN and MATHESON (1986) and have been considered in a number of scenarios (LINDGREN and MULlin, 1998; KANG, 2001; NIKKANEN and Ruotsalainen, 2000; Olsson et al., 2001, JoHnson and LIPOW, 2002). However, none of the studies focused on the deployment problem.

LINDGREN et al. (in press) compared Net gain from various orchard deployment strategies based on trunca- 
tion and linear deployment with and without restriction on relatedness. The study was based on real data of 11 full-sib families with two sibs from each family. Results showed the relative advantages of optimizing not only the proportions of the ramets but also the number of sibs to be included (one or two sibs) from each family. In certain cases, a simple restriction on relatedness in linear deployment of ramets turned to be as efficient as any other alternative. These results call for a more detailed examination of this case with a more realistic and complex scenario: higher number of families and seedlings within families to be tested for more parameters at a broader range of parameter values. In our study, by using efficient but more sophisticated deployment solution, we aim optimize deployment at all three levels of genetic material: number of families, number of individuals from each family (introducing the component of pairwise coancestry) and number of ramets from each individual (introducing self coancestry). When comparing the deployment strategies, we simultaneously consider the genetic gain and relatedness in the seed orchard expressed as "Net gain" index (DANUSEvičIUS and LINDGREN, 2002). Net gain expresses the average breeding value of the ramets adjusted for expected inbreeding depression and calculated from the coancestry between candidate clones.

The aim of the present study is to develop and investigate procedures to deploy tested, related genotypes to clonal seed orchards with variable numbers of ramets across a range of scenarios with simple relatedness patterns. Simulation procedures are used based on artificial data generated for half-sib families that provide the candidates pool for seed orchards. Results may help to guide forest tree breeders about the potential and application of the method over a range of circumstances.

\section{Material and Methods}

\section{Simulated data}

The data used in this study were simulated breeding values for unrelated half-sib families, which are considered as the candidates for deploying in a seed orchard (among and within family selection forward of the candidates in a half-sib progeny trial). Only this simple case for half-sib relatedness is explored in our study since it allows the general concept to be easily examined and is indeed a common situation in practical forest tree breeding. Recent developments towards paternal DNA fingerprinting may raise the efficiency of half-sib versus full- sib breeding strategy (GRATTAPAGLIA et al., 2004; GUPTA et al., 2005).

Order statistics were used to generate the "true" family and within family breeding values, expressed as standard deviations from the total mean set to 0 (LINDGREN and NiLsson, 1985). The breeding values were expressed as "units of coefficient of additive genetic variation $\left(C V_{A}\right)$ ). To combine the inbreeding depression and the genetic gain on the same unit scale a value has to be assigned to $C V_{A}$. Based on rough estimates used for Swedish conifer breeding (Rosvall et al., 2001) $C V_{A}$ was set at $10 \%$. The individual tree breeding values were predicted as:

$$
B V_{i, j}=C V_{f} *\left(\sqrt{0.25} * \xi_{i}+\sqrt{0.75} * \xi_{j(i)}\right)
$$

where:

$B V_{i, j}=$ breeding value of individual $j$ in family $i$.

$C V_{A}=$ coefficient of variation for breeding values.

$\zeta=$ order statistics of $\mathrm{i}$-th family and $\mathrm{j}$-th individual within i-th family.

\section{Key-parameters and simulation scenarios}

The optimization was carried out according to the main and alternative scenarios of the key-parameter values (Table 1). In our study, the main scenario values were tuned for the main commercial temperate and boreal forest tree species such as Scots pine. The status number of 12 for a seed orchard was chosen as the main scenario alternative since it is mathematically simple but still allows the parameters in the optimization procedure to be set at a similar order of magnitude to the first orchards established in Sweden where relatedness may be a consideration (census number around 25, status number around 15, LINDGREN and PRESCHER, 2005). When testing an alternative value of a parameter the values of the other parameters were kept at the main scenario values (except of the interactive scenario tuned for low-budget breeding: less and smaller families in the trials).

Status number $\left(N_{s d}\right)$, the number of unrelated and not inbred individuals desired in the seed orchard (expresses the desired level of gene diversity in seed orchard), was estimated according to the following formula:

$$
N_{s t}=0.5 / \Theta,
$$

where:

$\Theta=$ group coancestry.

Table 1. - Parameters for the main and the alternative simulation scenarios.

\begin{tabular}{lccc}
\hline \multicolumn{1}{c}{ Parameter } & $\begin{array}{c}\text { Main } \\
\text { Scenario }\end{array}$ & $\begin{array}{c}\text { Alternative } \\
\text { scenarios }\end{array}$ & $\begin{array}{c}\text { Interactive } \\
\text { scenario (low } \\
\text { budget) }\end{array}$ \\
\hline $\begin{array}{l}\text { Number of unrelated half-sib families } \\
\text { for candidate selection }\end{array}$ & 24 & $6,12,48$ & 12 \\
$\begin{array}{l}\text { Size of half-sib families (within } \\
\text { family selection intensity) }\end{array}$ & 40 & 20 & 5 \\
$\begin{array}{l}\text { Status number in seed orchard }\left(N_{x d}\right) \\
\text { Inbreeding depression }\end{array}$ & 12 & $3,6.24$ & 12 \\
\begin{tabular}{l} 
Number of clones \\
\hline
\end{tabular} & As found & As found & As found \\
\hline
\end{tabular}


The gene diversity available for deployment can conveniently be expressed via the ratio of the status number available over the status number desired in the seed orchard (abbreviated $N_{s a} / N_{s d}$ ratio): when it is high, there is a large diversity to select from. The status number available $\left(N_{s a}\right)$ was calculated for a number of half sib families by the approximation that a large half-sib family carries a status number of 4 . This is a somewhat rough approximation, the status number for half-sib families of size 20 is 3.5 and of size 40 is 3.7 , but the exact status number of the candidate population is not very critical, as the calculations are based on the group coancestry of the candidates and $N_{s a}$ serves for comparison only.

Group coancestry can be interpreted as the loss of the gene diversity in the wild forest by the implementation of tree breeding (LINDGREN and KANG, 1997; LINDGREN and Mullin, 1998 and Rosvall, 1999). Group coancestry of the orchard, considering the different proportion of clones, can be divided into two terms (LINDGREN and Mullin, 1998) as follows:

$$
\Theta=\sum_{r-1}^{n} p_{1}^{2} 0.5\left(1+F_{i}\right)+\sum_{i-1}^{n} p_{1} \sum_{j+i}^{n} p_{j} \theta_{i j}=\Theta_{S}+\Theta_{p}=0.5 / N_{s}
$$

where:

$$
\begin{aligned}
p_{i} & =\text { occurrence of clone } i \\
F_{i} & =\text { the coefficient of inbreeding for clone } i \\
\theta_{i j} & =\text { coancestry between clone } i \text { and clone } j \\
\Theta_{S} & =\text { self-coancestry; } \\
\Theta_{P} & =\text { pair-coancestry. }
\end{aligned}
$$

The first term expresses the self-coancestry, which depends on the number of ramets of a clone. The second term depends on the relatedness among different clones (pair-coancestry) and their occurrence in the orchard. We assumed that clones are not inbred $\left(F_{i}=0\right)$ and that only two levels of relatedness occur: None $(\theta=0)$ and half $\operatorname{sib}(\theta=0.125)$.

Net gain was considered as the parameter to be maximised. In our study, Net gain refers to the difference between the average breeding value of the ramets in the orchard adjusted for expected inbreeding depression and the average breeding value of the test, which is set to 100 to allow interpretation of the numbers as percentages. The Net gain is calculated as the average breeding value of seeds produced from the orchard with a deduction for the expected inbreeding due to matings between related clones:

$$
B V I=\left(1-D^{*} \Theta_{F}\right) \sum p_{i} g_{i}
$$

where:

$B V I$ is the predicted average breeding value of the ramets adjusted for the expected inbreeding (ignoring selfing).

$\left(1-I D^{*} \Theta_{P}\right)$ is a factor reducing the breeding values for inbreeding;

ID is the inbreeding depression "coefficient", which converts pair-coancestry to adjust for the expected inbreeding depression to the same scale as the breeding values. In this study, we assume no difference in inbreeding depression between orchard ramets and so set $I D=1$, which is a reasonable value for forest tree applications and can be interpreted that production will be zero if there is complete homozygosity (if $I D=1$ and pair-coancestry $=1$, then the term $\left(1-I D^{*}\right.$ pair coancestry) $=0$ and $B V I=0$ ).

A Net gain of 120 percent means that the selected group would provide $20 \%$ higher value of a target trait than the unimproved individuals.

\section{Deployment strategies compared}

- Truncation selection of unrelated half-sibs (abbreviated as Truncation unrelated). The single top-ranking individual is selected based on breeding value in each half-sib family, and all selections made are deployed in equal proportions. In terms of running the optimization procedure, the desired status number is set, the single best individual from each family above certain threshold breeding value is chosen, and equal numbers of ramets are produced from each of these selections for the orchard).

- Truncation selection allowing relatives (Truncation related). Top ranking individuals for breeding value are deployed in equal proportions regardless of relatedness (family affiliation). For the optimization procedure, the desired status number is set, individuals above a certain threshold are chosen and equal number of ramets from each is deployed);

- Linear deployment of unrelated half sibs (Linear deployment unrelated). Only the top-ranking individual in each family is considered for deployment. The selections are deployed in the proportions linearly related to their breeding value according to the following formula:

$$
p_{i}=\left(g_{i}-g_{0}\right) / g_{0}
$$

where:

$p_{i}=$ proportion of $\mathrm{i}$-th individual (number of ramets) in the seed orchard;

$g_{i}=$ breeding value of $\mathrm{i}$-th individual

$g_{0}=$ intercept of linear relationship (the threshold breeding value below which candidates are not selected).

- Linear deployment with no relatedness constraints (Linear deployment related). Individuals are deployed in the proportions linearly related to their breeding values (the same algorithm as for Linear deployment unrelated).

- Optimal deployment (Optimal deployment). Individuals are deployed in the proportions which maximize the Net gain at a given status number in the seed orchard. The optimal proportions were obtained by the aid of the Solver Tool in Excel. The Solver tool is essentially based on linear programming.

The deployment strategies were usually compared at the same status number.

\section{Simulation procedure and the calculation tool}

The number of half-sib families, the number of individuals from each family as well as number of ramets of each individual (expressed as proportion) to be included in the seed orchard were optimized to achieve maximum Net gain at a desired status number in the seed orchard 
$\left(N_{s d}\right)$. The desired $N_{s}$ was achieved by setting the truncation limit for breeding value (truncation, linear deployment strategies) or by linear programming to achieve maximum Net gain at a given $N_{s d}$ (optimal deployment strategy).

The following simplifying assumptions were made: no pollen contamination, no selfing, and contribution from the orchard to the offspring is proportional to the number of ramets of each clone (that is, equal fertility for each ramet and clone; KUMMAR et al. (2006) showed that fertility variation is poorly correlated with breeding values).

For the calculations MS EXCEL 2003 was used. Workbooks with a similar content as that used for this study can be found at the website: http://www.genfys.slu.se/ staff/dagl/.

\section{Results and Discussion}

\section{Comparison of the deployment strategies}

The Optimal proportion deployment strategy returned the highest Net gain at all scenarios considered here (Table 2). The Optimal proportion strategy produced 5\% greater Net gain than simple truncation selection for all scenarios except when there was no inbreeding depression and many candidates from many families were available (Table 2, Figure 1). Hence, it seems worthwhile to look for better strategies than simple truncation selection for breeding value for seed orchards in advanced generations as was anticipated from the study of unequal ramet numbers by LINDGREN and MATHESON (1986). The Optimal proportion deployment strategy was most efficient at the scenarios, which forced the selection of the related candidates (low family number at a fixed $N_{s d}$ or high desired $N_{s d}$ at a fixed family number) and at the interactive scenario (low within family selection intensity and low family number) (Figure 1).

Linear deployment unrelated was the second best approach in most cases (Table 2). The efficiency of the Linear deployment unrelated strategy was especially low when the number of families dropped to 12 at the desired $N_{s d}$ of 12 (i.e. $N_{s a}$ available dropped to 48 at $N_{s d}$ desired of 12).

In most cases, the Truncation unrelated strategy was the third ranking strategy (Figure 1). The strategies with no restriction on relatedness (Linear deployed related and Truncation related) were the least efficient strategies (Figure 1, Table 2). The Linear deployment related was slightly more superior over the Truncation related strategy at a higher $N_{s a} / N_{s d}$ ratio (Table 2).

The increased demand on diversity in the seed orchard (high $N_{s d}$ ) resulted in drop of the pair-coancestry for the Truncation and Linear deployment strategies and raise of the pair-coancestry for the Optimal proportion strategy (Figure 2). The Optimal proportion strategy and the other deployment strategies allowing relatedness use different strategies when dealing with increased demand for diversity in the seed orchard. This also may explain the relative advantage of Optimal proportions strategy. Before the demand on diversity is increased, Linear deployment samples individuals with high breeding value regardless of their relatedness leading to larger numbers of individuals from a few topranking families and high pair-coancestry (not shown). The Optimal proportion strategy optimizes the number of relatives and favors less sampling of relatives than the Linear deployment strategy (relatively less relatives from the few top ranking families) (Table 3). When the demand on diversity is increased (higher desired $N_{s d}$ ), the Optimal proportion deploys more individuals from

Table 2. - Net gain from seed orchards established with different deployment alternatives in the candidate populations composed of different number of families with different size and severity of inbreeding. Superiority of the Optimal proportions strategy to the second ranking strategy is given in the last column. $N_{s}$ is the desired status number in orchard.

\begin{tabular}{|c|c|c|c|c|c|c|c|c|c|c|}
\hline \multirow[b]{2}{*}{$\begin{array}{c}\text { Parame } \\
\text { ter }\end{array}$} & \multirow{2}{*}{$\begin{array}{c}\text { Fami } \\
\text { ly } \\
\text { num } \\
\text { buer }\end{array}$} & \multirow[b]{2}{*}{$\begin{array}{l}\text { Fami } \\
\text { ly size }\end{array}$} & \multirow[b]{2}{*}{$N_{s c t}$} & \multirow[b]{2}{*}{$\begin{array}{l}\text { Inbreed } \\
\text { ing } \\
\text { wcight }\end{array}$} & \multicolumn{5}{|c|}{ Net gain $(\%)$ from different deployment strategies } & \multirow{2}{*}{$\begin{array}{c}\text { Supcriofity } \\
\text { of Optimal } \\
\text { proportions } \\
\qquad \%\end{array}$} \\
\hline & & & & & $\begin{array}{c}\text { Optimal } \\
\text { proportion } \\
\mathrm{s}\end{array}$ & $\begin{array}{c}\text { Lincar } \\
\text { Deployme } \\
\text { nt }\end{array}$ & $\begin{array}{l}\text { Linear } \\
\text { Deployment } \\
\text { Unrelated }\end{array}$ & $\begin{array}{c}\text { Truncati } \\
\text { on }\end{array}$ & $\begin{array}{c}\text { Truncati } \\
\text { on } \\
\text { Unrelate } \\
\text { d }\end{array}$ & \\
\hline $\begin{array}{c}\text { Main } \\
\text { scenario }\end{array}$ & 24 & 40 & 12 & 1 & 123.2 & 121.6 & 123.2 & 121.6 & 122.6 & 100.0 \\
\hline \multirow{3}{*}{$\begin{array}{l}\text { Family } \\
\text { number }\end{array}$} & 6 & 40 & 12 & 1 & 115.1 & 114.4 & no value & 113.9 & no walue & J05.I \\
\hline & 12 & 40 & 12 & 1 & 120.1 & 118.5 & 1189 & 118.3 & 118.7 & 106.4 \\
\hline & 48 & 40 & 12 & 1 & 125.5 & 124.1 & 125.5 & 123.9 & 124.9 & 100.0 \\
\hline $\begin{array}{c}\text { Family } \\
\text { size }\end{array}$ & 24 & 20 & 12 & I & 120.7 & 119.3 & 120.7 & 119,2 & 120.0 & 100.0 \\
\hline \multirow{2}{*}{$\begin{array}{l}\text { Status } \\
\text { number }\end{array}$} & 24 & 40 & 8 & I & 124.6 & 122.6 & 124.5 & 122.9 & 124.0 & 100.1 \\
\hline & 24 & 40 & 18 & 1 & 121.8 & 120.6 & 121.5 & 120.4 & 120.8 & 101.2 \\
\hline \multirow{4}{*}{$\begin{array}{l}\text { Inbrecdit1 } \\
\text { g wejght }\end{array}$} & 6 & 40 & 12 & 0 & 117.0 & 116.7 & no walue & 116.1 & no valuc & 101.9 \\
\hline & 12 & 40 & 12 & 0 & 120.9 & 120.5 & 118.9 & $120 . \mathrm{l}$ & 118.7 & 102.1 \\
\hline & 24 & 40 & 12 & 0 & 123.6 & 123.2 & 123.2 & 122.9 & 122.6 & 101.5 \\
\hline & 48 & 40 & 12 & 0 & 125.7 & 125.4 & 125.5 & 125.0 & 124.9 & 100.7 \\
\hline $\begin{array}{l}\text { Fannily } \\
\text { number } \\
\text { and size }\end{array}$ & 12 & 5 & 12 & I & 111.2 & 110.3 & 110.3 & 1100 & 110.1 & 108.4 \\
\hline
\end{tabular}



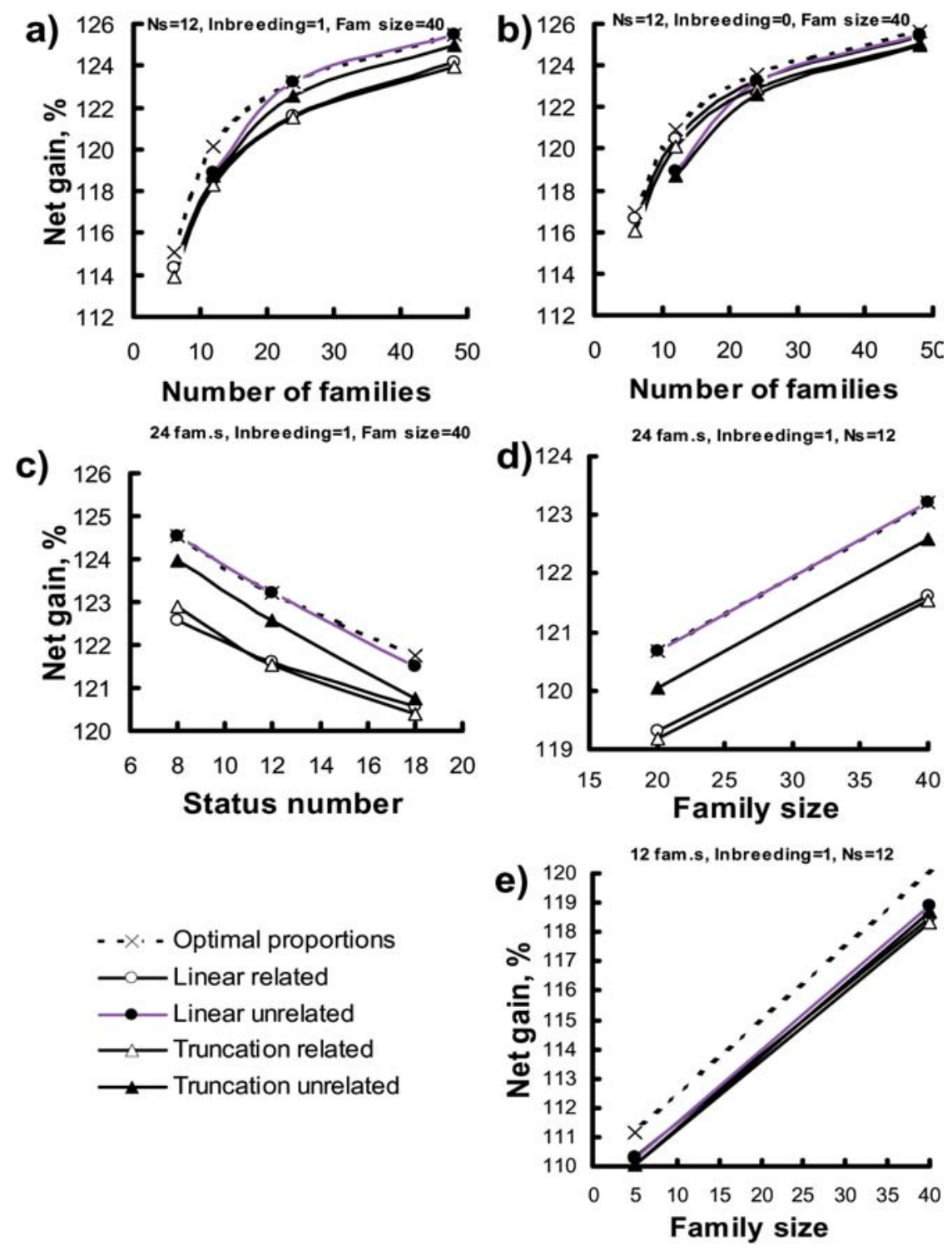

Figure 1. - Comparison of Net gain from the alternative deployment strategies under variable simulation scenarios.

the better families and optimizes their proportions to maximize Net gain. This causes gradual increase of paircoancestry (Figure 2). Whereas, to cope with the increased demand on diversity, the Truncation and Linear deployment strategies sample the top ranking individuals from the families of a lower rank, which are unrelated to the already sampled individuals. This causes reduction in pair-coancestry. This also explains the relatively lower efficiency of the Truncation and Linear deployment allowing relatedness over the same strategies with restriction on relatedness.

In certain situations, the efficiency of the Optimal proportion deployment strategy was not markedly different from that of the Linear Deployment unrelated strategy (Table 2). A technical disadvantage of the Optimal proportion strategy is that it requires a more complex software than practical breeders usually operate and the optimization procedure is more difficult to understand if compared with the Linear deployment strategy. Thus, it seems worthwhile to closer examine the cases where the

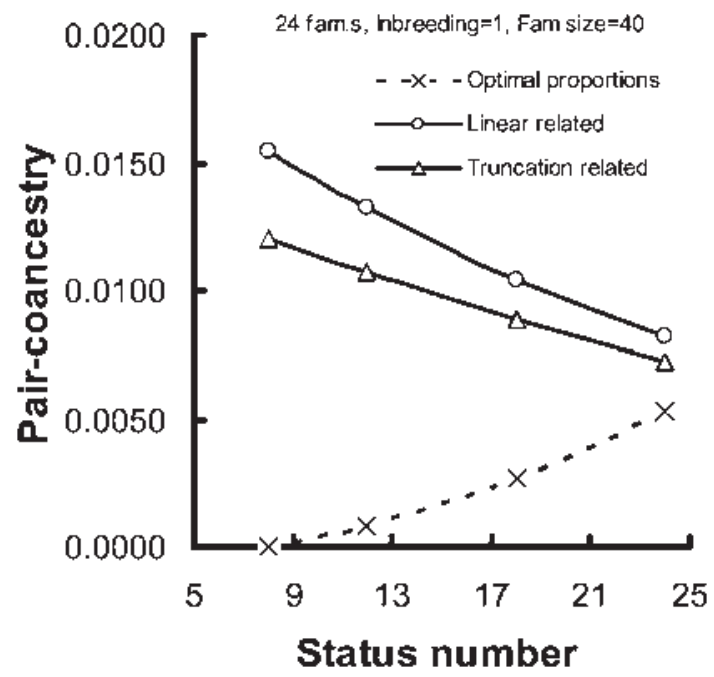

Figure 2. - Variation in pair coancestry in the deployed material depending on the status number desired in the seed orchard $\left(N_{s d}\right)$. Increase of pair-coancestry indicates deployment of relatives. 
Table 3. - Number of clones per family selected by the Optimum proportions strategy (helpful in constructing short-lists). Numbers in the column named 5 indicate number of families from each of which 5 clones were taken (the best families); 0- means no clones taken (the worst families). $N_{s a}$ is status number available, $N_{s d}$ is the status number desired.

\begin{tabular}{|c|c|c|c|c|c|c|c|c|c|c|c|}
\hline \multirow[t]{2}{*}{ Parameter } & \multirow{2}{*}{$\begin{array}{c}\text { Number of } \\
\text { families } \\
\text { (ratio } \\
N_{s d}^{r} / N_{s d} \text { ) }\end{array}$} & \multirow[t]{2}{*}{$\begin{array}{c}\text { Family } \\
\text { size }\end{array}$} & \multirow{2}{*}{$\begin{array}{c}\text { Status } \\
\text { number } \\
\text { desired } \\
\left(N_{s}\right)\end{array}$} & \multirow[t]{2}{*}{$\begin{array}{l}\text { Inbrecding } \\
\text { dcpression }\end{array}$} & \multirow[t]{2}{*}{$\begin{array}{l}\text { No. of } \\
\text { clones }\end{array}$} & \multicolumn{6}{|c|}{$\begin{array}{l}\text { No of families from which the number of } \\
\text { individuals given in table heading is sclected }\end{array}$} \\
\hline & & & & & & $\begin{array}{l}5 \text { best } \\
\text { Best }\end{array}$ & $\begin{array}{l}4 \text { best } \\
\text { iilies }\end{array}$ & 3 best & 2 best & I best & $\begin{array}{l}\text { Not } \\
\text { take }\end{array}$ \\
\hline \multirow{4}{*}{$\begin{array}{l}\text { Family } \\
\text { number }\end{array}$} & $6(2)$ & 40 & 12 & 1 & 28 & 4 & 2 & 0 & 0 & 0 & 0 \\
\hline & $12(4)$ & 40 & 12 & 1 & 21 & 0 & 0 & 2 & 5 & 5 & 0 \\
\hline & $24(8)$ & 40 & 12 & 1 & 18 & 0 & 0 & 0 & 2 & 14 & 8 \\
\hline & $48(16)$ & 40 & 12 & 1 & 18 & 0 & 0 & 0 & 0 & 18 & 30 \\
\hline $\begin{array}{l}\text { Family } \\
\text { size }\end{array}$ & $24(8)$ & 20 & 12 & 1 & 18 & 0 & 0 & 0 & i & 16 & 7 \\
\hline \multirow{3}{*}{$\begin{array}{l}\text { Status } \\
\text { number } \\
\text { desired } \\
\left(N_{\mathrm{sid}}\right)\end{array}$} & $24(12)$ & 40 & 8 & 1 & 12 & 0 & 0 & 0 & 0 & 12 & 12 \\
\hline & $24(8)$ & 40 & 12 & 1 & 18 & 0 & 0 & 0 & 2 & 14 & 8 \\
\hline & $24(5)$ & 40 & 18 & 1 & 29 & 0 & 0 & 1 & 7 & 12 & 4 \\
\hline \multirow{4}{*}{$\begin{array}{c}N_{\text {wd with }} \\
\text { variable } \\
\text { family } \\
\text { number }\end{array}$} & $6(8)$ & 40 & 3 & 1 & 4 & 0 & 0 & 0 & 0 & 4 & 2 \\
\hline & $12(8)$ & 40 & 6 & 1 & 8 & 0 & 0 & 0 & 0 & 8 & 4 \\
\hline & $24(8)$ & 40 & 12 & ] & 18 & 0 & 0 & 0 & 2 & 14 & 8 \\
\hline & $48(8)$ & 40 & 24 & 1 & 39 & 0 & 0 & 1 & 7 & 22 & 18 \\
\hline \multirow[t]{4}{*}{ Inbreding } & $6(2)$ & 40 & 12 & 0 & 27 & 4 & 1 & 1 & 0 & 0 & 0 \\
\hline & $12(4)$ & 40 & 12 & 0 & 25 & 1 & 1 & 2 & 3 & 4 & 1 \\
\hline & $24(8)$ & 40 & 12 & 0 & 22 & 0 & 0 & 2 & 4 & 8 & 10 \\
\hline & $48(16)$ & 40 & 12 & 0 & 21 & 0 & 0 & 1 & 3 & 12 & 32 \\
\hline
\end{tabular}

Linear Deployment unrelated may replace the Optimal proportions deployment. The basic difference between these two strategies is that Linear deployment considers the breeding value only, whereas, Optimal proportion is searching for the combination of genetic gain and relatedness to maximize the Net gain and in this way it takes account the relatedness of the candidates. Therefore, in cases when there were more families to select from, there was no marked difference between Optimal proportions and Linear deployment unrelated strategies, because both tended to select one top ranking individual in each family (Figure 1, Table 3). However, fewer available families (low genetic diversity available for deployment) forced the selection of relatives and the Optimal proportion strategy was more efficient to optimize the numbers of the related half-sibs.

Is there any threshold value for the genetic diversity available for deployment, which may help to choose between the Optimal deployment and the Linear proportions unrelated? The reduction of diversity available for deployment was simulated by (a) reducing the family number available for deployment at a constant status number desired in the seed orchard $\left(N_{s d}\right)$ (Figure 1ab) or (2) by increasing $N_{s d}$ at a constant family number available for deployment (Figure 1c). The threshold value for the number of families below which the Optimal proportion strategy became more efficient than Linear deployment unrelated was 24 (Figure 1a). This threshold value may expressed via the status number as follows: when the status number available $\left(N_{s a}\right)$ is for 8 times higher than the status number desired in the seed orchard $\left(N_{s d}\right)$ $\left(N_{s a}\right.$ of large 24 half sib families is 96 ; which is 8 time less than the desired $N_{s d}$ of 12 ). Thus, the Optimal proportion deployment is recommended to optimize numbers of related candidates when the $N_{s a}$ of the candidates is less than 8 times greater than $N_{s d}$. On the other hand, if there is a large diversity to select from $\left(N_{s a}\right.$ for more than 8 greater than $N_{s d}$ ), a good solution is just to constrain against relatives and deploy the clones proportionally to their breeding value (Linear deployment unrelated strategy). Usually, half-sib family trials consist of unrelated half-sibs and the desired orchard diversity varies about the status number of 12 . Then, the above given rule of thumb can be used to choose the deployment method.

Such random factors as unequal paternal contribution may also be considered when deciding on the deployment: group coancestry of the candidates may be higher when some of the half-sibs are fertilised by the same male-parent. It may be an argument to use the Optimal proportions deployment strategy, which is more efficient at higher levels of relatedness in the candidate population.

\section{Effect of the parameters}

At a constant desired status number in the orchard, increase of the family number in the candidate population returned higher Net gain (Table 2, Figure 1ab). This was caused by a higher among family selection intensity and lower reduction of net gain because of less related- 
ness. This is an argument for using a large number of families in tree improvement (as discussed by HoDGE and WHITE, 1993).

At a constant status number desired in the orchard $\left(N_{s d}\right)$, reduction of family number in the candidate population increased the superiority of the Optimal deployment strategy (Table 2, Figure 1a) and led to deployment of more related individuals (Table 3). For instance, in case of 12 half-sib families, 3 individuals were selected from each of the 2 best families, 2 individuals were selected from each of 5 families of the correspondingly lower rank and 1 individual was selected from the remaining 5 families (Table 3 ). In case of 24 families, 2 individuals were selected from each of the best 2 families; 1 individual was selected from each of the remaining 14 families and 8 families were not sampled at all (Table 3). The same pattern was observed, when the desired status number $\left(N_{s d}\right)$ was varied at a constant family number: less available diversity led to a higher relative efficiency of the Optimal proportion deployment (Table 3).

The reduction of number of families for deployment forced selection of relatives, and this was least favorable for the strategies, which do not consider relatedness (Linear unrelated and Truncation unrelated, Figure 1a). Second note is that in case of the Optimal proportions at the main scenario, eight of 24 families were not sampled and more or less one individual was selected from each of the remaining families. This indicates that (1) the diversity of 24 families ( $N_{s}$ of $24 \times 4=96$ ) was more than enough to achieve the optimum balance between the gain in inbreeding when the desired status number in the orchards was 12 (ca eight times less than the $N_{s}$ available) and (2) in such cases, the optimization strategy is similar to Linear deployment unrelated (only one best individual is sampled from certain number of the best families). Thus, if the available status number $\left(N_{s a}\right)$ is for more than eight times greater than the desired status number $\left(N_{s d}\right)$, a more transparent Linear deployment strategy can be used with restriction on relatedness (one best within each family deployed proportionally to the breeding value of the family). The relationship between the number of the deployed clones and the $N_{s a} / N_{s d}$ ratio supports the same threshold value of eight for $N_{s a} / N_{s d}$ ratio to choose Optimal proportions rather than Linear deployment strategy (Figure $3 a$ ).

In general, inbreeding had a weak effect on Net gain (Table 2), because the gene diversity in the candidate population was high enough to maintain low degree of relatedness in the deployed population. Thus, the expected average coefficient of inbreeding in the harvested seeds would be low, and severe inbreeding depression would not occur. The Net gain will thus only be marginally affected by the value of the parameter ID, which indicates the severity of inbreeding depression when inbreeding really occurs. The magnitude of inbreeding had no marked affect on the gain achievable from Optimal proportion strategy (Table 2), conversely, the severity of inbreeding favored the strategies without restriction on relatedness, which could deploy related half-sibs with a higher breeding value. Ignoring the inbreeding depression led to more selections of relatives among better families (Table 3). However, when the desired $N_{s d}$ became much smaller than the available $N_{s a}$ in the candidate population, number of selected family members did not become larger than 3 (Table 3). Why did the efficiency of the strategies with restriction on relatedness markedly dropped at the scenarios with low family number and no inbreeding depression? When there are fewer families to select from, there are two ways to satisfy the desired $N_{s d}$ : (1) include more (but inferior) families or/and (2) increase the number of related half sibs. The strategies without restriction on relatedness can do both; the strategies with restriction can just sample more families and equalize the proportions of ramets from each family. However, this decrease of relatedness does not compensate the reduction of breed-

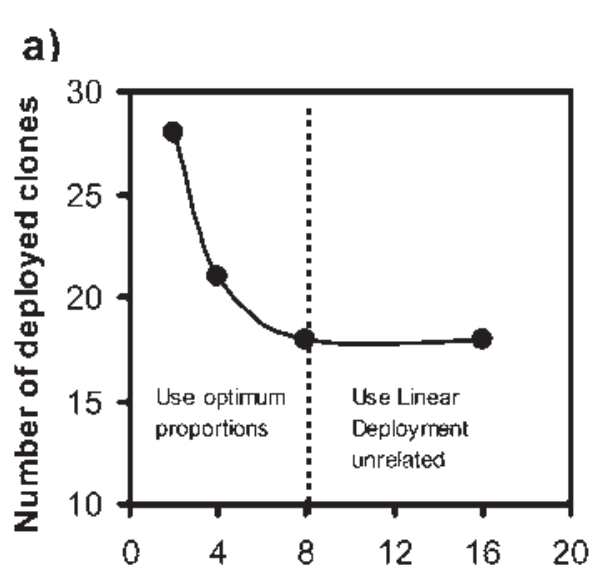

Ratio $\mathbf{N}$ s availabe/ $\mathbf{N}$ s desired b)

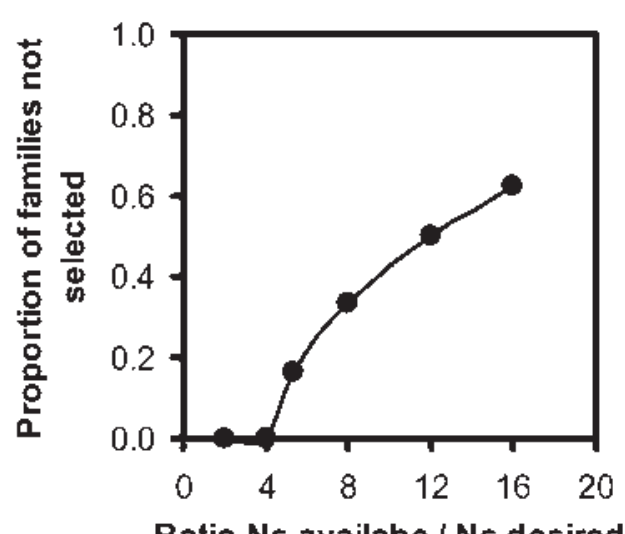

Ratio Ns availabe / Ns desired

Figure 3. - (a) when to use Optimal proportions (OP) and Linear Deployment unrelated (LDU) strategies: the dependence of the number of deployed clones on the diversity available for deployment (expressed as ratio $N_{s a} / N_{s d}$ ). When number of deployed clones is constant, one best individual was selected from certain number of superior families and then $\mathrm{OP}=\mathrm{LDU}$; (b) how much diversity we need for $N_{s d}$ of 12 (usual case)? When $N_{s a}$ is for 4 times greater than $N_{s d}$, all families are needed (12 half-sibs families at $N_{s d}$ of 12). 
ing value. Thus, in case of low diversity to select from, the deployment strategies with no restriction on relatedness may be used. This observation is confirmed by the scenario, where inbreeding was not considered (Figure $1 b)$ : selection of more related half-sibs from the topranking families is more efficient than selection of less related individuals with a lower breeding value.

Increase of within family selection intensity (that corresponds to family size in the tests) improved Net gain from all the deployment strategies with an equal magnitude and caused selection of more related individuals (Figure 1d). Simultaneous reduction of family number and family size (simulating low budget scenario) had no effect on the relative efficiency of the strategies (Figure 1e).

\section{The number of clones and short-list of families}

The total number of clones deployed was never higher than 40 (Table 3). The largest number of clones was obtained in the scenarios where high diversity requirement forced selection more families (Table 3, scenario with 48 families for $N_{s d}$ of 24). For a more realistic scenario with the desired $N_{s d}$ of 12 , the optimum number of clones varied at about 20 (Table 3 ). At constant $N_{s d}$ of 12 , doubling the family number form 24 to 48 (corresponding the raise of the $N_{s a} / N_{s d}$ ratio from 8 to 12) did not affect the optimum number of the deployed clones (Table 3). Thus, if $N_{s d}$ of 12 can be accepted as sufficient diversity level in the new seed orchards, then not more than 20 clones are needed. LINDGREN and PRESCHER (2005) optimized number of tested clones in the seed orchards and suggested a similar figure of 20 clones for the first cycle of orchards comprising tested clones given similar conditions as in our study.

The short-lists of families to be included in the orchards can be much shorter if desired status number is low (Table 3). If the status number of the candidate population is high, the Optimal proportion strategy simply takes the best individual within each family and optimizes the proportions in a similar way as linear deployment does (Table 3). This means that if there are many families, the simplest and most efficient approach to deploy the clones for seed orchards is to select the best individual within each family and deploy tem linearly to their breeding values.

The short lists can be constructed by the aid of Table 3 and Figure $3 b$ : (i) if the $N_{s a}$ (available) is for more than 4 times greater than the $N_{s d}$ (desired), not all families will be sampled (Figure 3b), (ii) if $N_{s a}$ is for 8 (10) times greater than the $N_{s d}$, then the rule of deployment is simple: discard $1 / 2$ worst families and deploy one best individual within each of the remaining $1 / 2$ best families with the proportions linearly related to their breeding value (Table 3, Figure $3 a$ ), (iii) if the $N_{s a}$ is for 16 times greater than $N_{s d}$, then sample one best individual with each of $1 /{ }_{3}$ of the best families and use linear deployment according to the breeding value (Table 3). This concept can also be used to set a threshold $N_{s d}$ value for discrimination between the Optimum proportions and Linear deployment unrelated strategies (see the discussion section). At the constant $N_{s a} / N_{s d}$ ratio, increase family number (increase of additive variance) resulted in sampling more relatives from the better families (Table 3).

\section{Conclusions}

If there is a large number of unrelated half-sib families available for deployment to seed orchards (e.g. status number available among candidates is at least 8 times greater than the status number desired in the seed orchard), the best advice is to use linear deployment unrelated strategy: take the single best candidate from the best families and deploy the ramets linearly according to the individual breeding values. The number of families to select from can be selected to satisfy the desired status number. If such large reduction of diversity is not tolerable or the candidates tend to be related, optimization with the Optimal proportions strategy is recommendable.

\section{References}

DANusEviČIIUs, D. and D. LINDGREN (2002): Efficiency of Selection Based on Phenotype, Clone and Progeny Testing in Long-term Breeding. Silvae Genetica 51: 19-26.

Grattapaglia, D., V. J. Ribeiro and G. D. S. P. Rezende (2004): Retrospective selection of elite parent trees using paternity testing with microsatellite markers: an alternative short term breeding tactic for Eucalyptus. Theoretical and Applied Genetics 109 (1): 192-199.

GuPta, A. K., B. Y. Kang, J. K. RoY and O. P. RAJorA (2005): Large scale development of selectively amplified microsatellite polymorphic loci (SAMPL) markers in spruce (Picea). Mol. Ecol. Notes 5 (3): 481-483.

Hodge, G. R. and T. L. White (1993): Advanced-generation wind-pollination seed orchard design. New Forestry 7: 213-236.

Johnson, R. and S. LIPOW (2002): Compatibility of breeding for increased wood production and long-term sustainability: the genetic variation of seed orchard seed and associated risks. In: Proceedings wood compatibility initiative workshop 18, p. 169-179.

KANG, K. S. (2001): Genetic gain and gene diversity of seed orchard crops. Ph.D thesis. Acta Universitatis Agriculturae Sueciae Silvestria 187.

KJÆR, E. D. (1995): Assessment of genetic variation in clone seed plantations- illustrated with an example from Sitka spruce. Dansk Skovbruks Tidskrift 80: 57-77.

Kumar, S., S. Gerber, T. E. Richardson and L. Gea (2007): Testing for unequal paternal contributions using nuclear and chloroplast SSR markers in polycross families of radiata pine. Tree Genetics and Genome 3: 207-214.

LINDGREN, D. (1974): Aspects of suitable number of clones in a seed orchard. Proc. of the IUFRO joint meeting of working parties on population and ecological genetics, breeding theory and progeny testing. Stockholm, the Royal College of Forestry, Stockholm, Sweden. p 293-305.

LINDGREN, D. and J.-E. NILSSON (1985): Calculations concerning selection intensity. Department of Forest Genetics and Plant Physiology. Swedish University of Agricultural Sciences. Report No. 5.

LindGren, D. and A. C. MAtheson (1986): An algorithm for increasing the genetic quality of seed from seed orchards by using the better clones in higher proportions. Silvae Genetica 35: 173-177. 
LINDGREN, D. and K.-S. KANG (1997): Status number - a useful tool for tree breeding. Research Report of the Forest Genetic Research Institute of Korea 33, pp. 154-165.

LindGRen, D. and T. J. Mullin (1998): Relatedness and status number in seed orchard crops. Can. J. For. Res. 28: $276-283$.

Lindgren, D. and F. Prescher (2005): Optimal clone number for seed orchards with tested clones. Silvae Genetica 54: 80-92.

Lindgren, D., O. Rosvall and D. DanusevičIUs: Unequal deployment of clones to a seed orchard when candidates are related (submitted manuscript).

NIKKANEN, T. and S. RUOTSALAINEN (2000): Variation in flowering abundance and its impact on the genetic diversity of the seed crop in a Norway spruce seed orchard. Silva Fennica 34: 205-222.

OLSSON, T. (2001): Parameters, relationship and selection in Pines. Doctoral thesis. Swedish University of Agricultural Sciences, Umea, Silvestria 192, 27 p. (and 4 papers).
Olsson, T., D. LindGRen and B. Li (2001): Balancing genetic gain and relatedness in seed orchards. Silvae Genetica 50: 222-227.

Rosvall, O. (1999): Enhancing Gain from Long-Term Forest Tree Breeding while Conserving Genetic Diversity. Ph.D thesis. Acta Universitatis Agriculturae Sueciae. Silvestria 109.

Rosvall, O., G. Jansson, B. Andersson, T. Ericsson, B. Karlsson, J. Sonesson and L.-G. Stener (2001): Genetic gain from present and future seed orchards and clone mixtures. Rep. of the For. Res. Inst. of Sweden 1: 36-41. ISSN 1103-4580.

Wang Tongli, S. N. Aitken, J. H. Woods, K. R. Polssson and S. MAGNussen (2003): Effects of inbreeding on coastal Douglas fir growth and yield in operational plantations: a model-based approach. Theor. Appl. Genet. 108: 1162-1171.

Woods, J. H. and J. C. HEAman (1989): Effect of different inbreeding levels on filled seed production in Douglasfir. Can. J. For. Res. 19: 54-59.

ZoBel, B. and J. TALBERT (1984): Applied forest tree improvement. Wiley, Prospect Heights, Ill.

\title{
Crossability Between Wild (Malus sylvestris) and Cultivated (M. x domestica) Apples
}

\author{
By A. S. LARSEN ${ }^{1), *}$, M. JenseN ${ }^{2)}$ and E. D. KJÆR ${ }^{1)}$
}

(Received $25^{\text {th }}$ October 2006)

\begin{abstract}
Malus sylvestris, a native fruit tree of Europe, is believed to be threatened by hybridization with the omnipresent cultivated apple (Malus $\mathrm{x}$ domestica). In the present study a series of controlled crossings were carried out in order to establish whether $M$. sylvestris can hybridize with its near relative, $M$. x domestica. By looking at fruit set, seed production, germination percentages, and development of seedlings following inter- and intraspecific crossings, no indication of neither pre- nor postzygotic barriers to hybridization between the two species was found. This can have important implications for management of the genetic resources of $M$. sylvestris.
\end{abstract}

Key words: Malus sylvestris, Malus x domestica, crossability, hybridization, conservation.

\section{Introduction}

The European crab apple (Malus sylvestris (L.) Mill.) is an insect pollinated species native to most of conti-

1) Division for Forest Genetic Resources, Copenhagen University, Hørsholm Kongevej 11, DK-2970 Hørsholm, Denmark.

2) Department of Horticulture, Århus University, Kirstinebjergvej 10, DK-5792 Årslev.

*) Corresponding author: Phone: +45 353316 53, Fax: +45 3533 15 17. E-mail: ansl@life.ku.dk. nental Europe and the British Isles. Within its natural range, the species is considered threatened due to habitat modifications and hybridization with the cultivated apple (Malus $\mathrm{x}$ domestica Borkh.). The latter has been suggested due to the great ability for hybridization between species within the genus (KORBAN, 1986) but also due to the occurrence of morphologically intermediate phenotypes in nature (STEPHAN et al., 2003). The issue of hybridization has traditionally been studied by use of morphological characters - in particular pubescence. Ontogenetic and phenotypic variation however, is likely to hamper such studies. Therefore, these studies have recently been supplemented by molecular studies which demonstrate that it is still possible to find genetically authentic populations of $M$. sylvestris with only small traces of hybridization or introgression (COART et $a l .$, 2003; WAGNER et al., 2004; LARSEN et al., 2006). At least this is true for the more or less dense populations that have been included in the reported studies.

Despite the great interest in studying the occurrence of hybrids between the two species in nature, very little is known about the actual ability of the two species to hybridize. Thus, to the knowledge of the authors no published studies exist that quantify the crossability between the two species directly. In the present study, we therefore tested the hypothesis that $M$. sylvestris has 